\title{
Cryogenic EBSD on ice: preserving a stable surface in a low pressure SEM
}

\author{
I. WEIKUSAT*, D. A. M. DE WINTER $\dagger$, G. M. PENNOCK $\ddagger$, \\ M. HAYLES $\S$, C. T. W. M. SCHNEIJDENBERG $\dagger \&$ \\ M. R. DRURY $\ddagger$ \\ * Alfred Wegener Instit. Polar\&Marine Res., Bremerhaven, Germany \\ $\dagger$ Faculty of Science, Utrecht University, TA Utrecht, The Netherlands \\ $\ddagger$ Faculty of Earth Science, Utrecht University, TA Utrecht, The Netherlands \\ $\S F E I$ Co. Nanoport, Achtseweg Noord 5, KA Eindhoven, The Netherlands
}

Key words. charging, cryo SEM, EBSD, ice, microstructure mapping, misorientation, subgrain boundary, sublimation etching, sublimation.

\section{Summary}

Naturally deformed ice contains subgrains with characteristic geometries that have recently been identified in etched surfaces using high-resolution light microscopy (LM). The probable slip systems responsible for these subgrain boundary types can be determined using electron backscattered diffraction (EBSD), providing the etch features imaged with reflected LM can be retained during EBSD data acquisition in a scanning electron microscope (SEM). Retention of the etch features requires that the ice surface is stable. Depending on the pressure and temperature, sublimation of ice can occur. The equilibrium temperature for a low pressure SEM operating at $1 \times 10^{-6} \mathrm{hPa}$ is about $-112^{\circ} \mathrm{C}$ and operating at higher temperatures causes sublimation. Although charging of uncoated ice samples is reduced by sublimation, important information contained in the etch features are removed as the surface sublimes. We developed a method for collecting EBSD data on stable ice surfaces in a low pressure SEM. We found that operating at temperatures of $<-112^{\circ} \mathrm{C}$ reduced sublimation so that the original etch surface features were retained. Charging, which occurred at low pressures $(<1.5 \times$ $10^{-6}$ to $\left.2.8 \times 10^{-5} \mathrm{hPa}\right)$ was reduced by defocusing the beam. At very low pressures $\left(<1.5 \times 10^{-6} \mathrm{hPa}\right)$ the spatial resolution with a defocused beam at $10 \mathrm{kV}$ was about $3 \mu \mathrm{m}$ in the $x$-direction at $-150^{\circ} \mathrm{C}$ and $0.5 \mu \mathrm{m}$ at $-120^{\circ} \mathrm{C}$, because at higher temperature charging was less and only a small defocus was needed to compensate it. Angular resolution was better than $0.7^{\circ}$ after orientation averaging. Excellent agreement was obtained between LM etch features and EBSD mapped

Correspondence to: I. Weikusat, Alfred-Wegener-Instit. Polar\&Marine Res., Am Alten Hafen 26, 27568 Bremerhaven, Germany. Tel: +49-471-4831-1968; fax: +49-471-4831-1271; e-mail: ilka.weikusat@awi.de microstructures. First results are shown, which indicate subgrain boundary types comprised of basal (tilt and twist) and nonbasal dislocations (tilt boundaries).

\section{Introduction}

Ice occurs in huge masses in the polar regions and plays a crucial role in our climate system, which can affect the sea level evolution by ice discharge, involving iceberg calving and release of melt water (Bindoff et al., 2007; IPCC, 2007; Lemke et al., 2007). Unlike other factors influencing sea level changes, such as thermal expansion of the ocean water, the contribution by ice discharging into the oceans cannot, as yet, be adequately predicted, because the flow of ice sheets is still poorly understood. Ice flow involves two major processes: basal sliding over bedrock, (Vaughan \& Arthern, 2007), and internal deformation including recrystallization processes. These two processes control the spreading of the ice towards the coast and thus drainage into the oceans. Recent ice sheet models are based on Glen's flow law (see review by Huybrechts, 2007), which describes the ice deformation on a macroscopic scale, but does not include the physical processes involved in deformation. Information on crystallographic slip systems, based on experimentally deformed ice and microstructures of natural ice is needed to understand the deformation related processes.

Ice microstructures can be characterized using light microscopy (LM) and X-ray techniques (e.g. Wang \& Azuma, 1999; Montagnat et al., 2003; Miyamoto et al., 2005; Kipfstuhl et al., 2006, 2009). These studies provide useful information on the orientation of $c$ - and $a$-axes and on grain shapes and grain sizes in natural polar ice, with typical grain sizes from 0.1 to $>10 \mathrm{~cm}$. A high resolution $\left(3 \mu \mathrm{m}\right.$ pixel $\left.^{-1}\right) \mathrm{LM}$ fast 
microstructure mapping method was developed (Kipfstuhl et al., 2006) to characterize ice microstructures in large, etched sections (up to $5 \times 11 \times 0.5 \mathrm{~cm}$ ). Three distinct subgrain boundary geometries were identified from statistical analyses of these images: subgrain boundaries were either parallel or perpendicular to the basal plane or had a zigzag geometry (Hamann et al., 2007; Weikusat et al., 2009a, 2009b). High-resolution electron backscattered diffraction (EBSD) mapping of crystal orientations and subgrain traces of etched surfaces are needed to calibrate these subgrain boundary geometries and to identify active slip systems. EBSD of ice has been obtained using a cold stage in the scanning electron microscope (SEM) (Iliescu et al., 2004). Texture and misorientation data was determined from manually selected EBSD patterns on uncoated, natural ice (Obbard et al., 2006; Obbard \& Baker, 2007) and from high resolution EBSD mapping on naturally and experimentally deformed ice (Piazolo et al., 2008). In these studies, a correlation was made between transmitted polarization LM images and EBSD data.

Sampling the changes occurring in deformation microstructures along a $3 \mathrm{~km}$ ice core using LM, let alone EBSD, is demanding. Grain sizes in natural ice are often quite large, which limits the number of grains that can be studied in a single sample, especially when using a cold stage in an SEM. In addition, deformation and recrystallization microstructures are very heterogeneously distributed within polycrystalline ice subjected to a wide range of deformation conditions (Kipfstuhl et al., 2006). Thus, locating subgrains in coarse-grained samples is demanding. The heterogeneity arises because hexagonal ice is strongly anisotropic: slip along basal planes is about 60 times easier to activate than nonbasal slip (Duval et al., 1983). Furthermore, the threshold misorientation, thus energy, that separates grain boundary behaviour from subgrain boundary behaviour, is very low for ice, $\sim 4-5^{\circ}$, (Suzuki, 1970; Obbard et al., 2006; Weikusat et al., 2010), compared to $10-15^{\circ}$ for other materials (de Meer et al., 2002; Humphreys \& Hatherley, 2004): thus discerning low angle subgrain boundaries from a bent lattice in naturally deformed ice can be very difficult using classical transmitted LM with crossed polarizers, in which only misorientations greater than about $2^{\circ}$ can be measured. Therefore, only a few studies to date have focused on low-angle boundaries in deformed polar ice (Durand et al., 2008; Weikusat et al., 2009a, 2010), although several others mention their occurrence and importance (e.g. Alley et al., 1995; Wang et al., 2003).

In order to characterize the deformation microstructures along polar ice cores, results from the large-scale LM microstructure mapping of etched surfaces and results from EBSD need to be combined. LM microstructure mapping provides a statistical database of the subgrain boundary types and helps locating and selecting the relevant features for EBSD sample analysis, whereas grain orientations and slip systems can be determined using EBSD. This combined approach

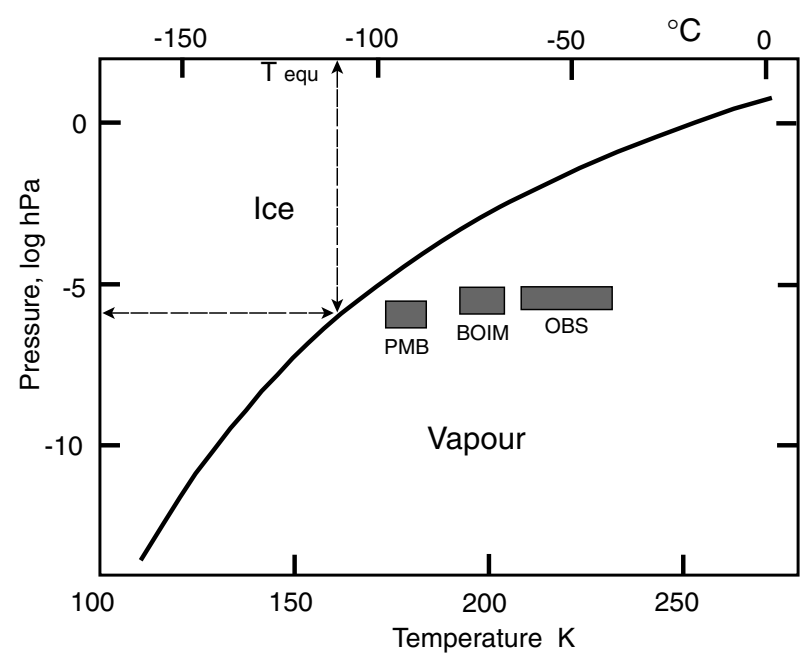

Fig. 1. Equilibrium phase diagram showing stability conditions for ice and ice in equilibrium with water vapour in a closed system (after Andreas, 2007). The equilibrium temperature for a chamber pressure of $1 \times 10^{-6}$ $\mathrm{hPa}$ is about $-112^{\circ} \mathrm{C}$. The SEM chamber pressure and stage temperature conditions of published EBSD studies on ice are shown as shaded blocks. PMB = Piazolo et al. (2008), BOIM = Baker et al. (2007), OBS = Obbard et al. (2006).

requires that the etched sample surface mapped in LM is retained in the SEM for the duration of the EBSD analyses.

In order to retain the ice sample surface in an SEM the pressure and temperature conditions need to be considered, as these parameters influence the thermodynamics and kinetics of sublimation and condensation. This is particularly important if the aim is to correlate etch features identified by LM microstructure mapping with EBSD. This correlation requires either that sublimation does not occur, or only under very slow kinetics. Fig. 1 is a plot of pressure versus temperature, showing the equilibrium conditions for solid ice and the partial vapour pressure for ice in a closed system (data from Andreas, 2007). Ice is stable in the ice phase field and unstable in the vapour phase field where sublimation occurs. The boundary between these two fields defines the ice-water vapour equilibrium conditions. Under high vacuum SEM conditions, with a typical chamber pressure of about $1 \times 10^{-6}$ $\mathrm{hPa}$, the equilibrium temperature occurs around $-112^{\circ} \mathrm{C}$ (dotted line in Fig. 1). At this pressure and temperature, in a closed system, the condensation rate equals the sublimation rate and thus an ice sample does not gain or lose material. Conditions reported for EBSD on ice (temperatures in the range of -40 to $-90^{\circ} \mathrm{C}$ and a chamber pressure in the region of $10^{-6}$ to $10^{-7} \mathrm{hPa}$ ) are also shown in Fig. 1 (Iliescu et al., 2004; applied by Obbard et al., 2006; Obbard \& Baker, 2007; Piazolo et al., 2008). Note that the chamber pressure is given in the literature and not the partial vapour pressure of water in the SEM chamber: the partial vapour pressure may be lower than the chamber pressure. These pressuretemperature conditions are in the water vapour field and ice 
is unstable and sublimes. The rate of sublimation is estimated to be about $0.5 \mu \mathrm{m} \mathrm{min}{ }^{-1}$ at $-100^{\circ} \mathrm{C}$ and $>1 \mu \mathrm{m} \mathrm{min}^{-1}$ at $>-90^{\circ} \mathrm{C}$ (Davy \& Branton, 1970; Barnes et al., 2002; Waller et al., 2005). This sublimation rate would cause a loss of about 50 to $500 \mu \mathrm{m}$, respectively, from the sample surface over an $8-9 \mathrm{~h}$ period, which is typically the timescale required to characterize subgrain boundaries in a $1 \mathrm{~cm}^{2}$ ice sample using EBSD. This loss is enormous, when compared to the scale of the substructures, such as the subgrain boundary networks, in which the boundaries are separated by about $10 \mu \mathrm{m}$ (see for an example fig. 1 in Weikusat et al., 2009a). Therefore, the etch features characterized using high resolution LM (Weikusat et al., 2009b) would be removed by sublimation in the SEM and it would no longer be possible to correlate the EBSD mapped microstructures with LM mapped microstructures. However, the advantage of sublimation is that the released water vapour counteracts charging (Iliescu et al., 2004).

The aim of this work is to develop an alternative technique for the collection of cryo-EBSD data on polar ice substructures that involves operating in the ice stability field in a low pressure (high vacuum) SEM such that the sample surface microstructure remains stable during data acquisition and the fine scale etch features are retained. Sublimationcondensation behaviour in an SEM is discussed. Operating at lower temperatures in the range -103 to $-170^{\circ} \mathrm{C}$ was found to reduce sublimation; the influence of defocusing the beam was examined as a means of reducing charge on uncoated samples instead of subliming the surface. An assessment of charging in EBSD patterns was made for both focused and defocused beam conditions for different chamber pressures using nitrogen gas. An assessment of the spatial and angular resolution of EBSD mapped microstructures using a defocused beam is also made. Methods for reducing the formation of frost deposition during sample transfer from the cold room into the SEM chamber and during EBSD mapping are presented. These procedures enabled examination of samples in the SEM for several hours and also avoided rapid deterioration of EBSD patterns caused by the development of a frost layer.

\section{Material and methods}

\section{Material}

The samples originated from the deep EPICA Dronning Maud Land ice core (EDML) and from a shallow ice core (B37), which were drilled between 2003 and 2006 at Kohnen station $\left(75^{\circ} 00^{\prime} 06^{\prime \prime} \mathrm{S}, 0^{\circ} 04^{\prime} 04^{\prime \prime} \mathrm{E}, 2892 \mathrm{~m}\right)$ East Antarctica (Oerter et al., 2009). The EDML drill site is located on a flank with a horizontal surface flow velocity of $0.76 \mathrm{~m} \mathrm{year}^{-1}$ (Wesche et al., 2007). The cores were stored at $-30^{\circ} \mathrm{C}\left(0.89 \mathrm{~T}_{\mathrm{m}}\right.$ homologous temperature) after transportation at $-25^{\circ} \mathrm{C}$ to Bremerhaven, where sections were prepared in a $-25^{\circ} \mathrm{C}$ cold laboratory. Sections were cut parallel to the long axis of the core $(\sim 50 \times 100 \mathrm{~mm})$. Standard microtome techniques were used to polish the sections, which were then etched by subliming the surface. Microstructures were mapped using reflected LM (Kipfstuhl et al., 2006). Typical and interesting areas were selected and small specimens for the SEM $(\sim 8 \times$ $8 \times 5 \mathrm{~mm}$ ) were cut using a handsaw. These small blocks were again polished by microtoming and sublimation and a further LM microstructure mapping step was performed. Polished specimens were tightly wrapped in plastic bags and stored in solid carbon dioxide (dry ice) at about $-70^{\circ} \mathrm{C}$ to reduce further sublimation during transfer (about 2 days to 3 weeks), before carrying out electron microscopy studies at Utrecht University.

\section{Instrumentation}

A FEI Nova Nanolab 600 was used, equipped with an EBSD detector (Oxford Instruments HKL Technology, Abingdon, U.K.), a cryo-preparation station and a cryo-SEM stage (Quorum Technologies Ltd, Ringmer, U.K.). The cryo-stage was installed $24 \mathrm{~h}$ prior to experiments to reduce the water content in the chamber. The standard Quorum cold trap was located around the electron column pole piece, about $5 \mathrm{~mm}$ above the sample surface. A blank plate on the SEM chamber was also cooled to liquid nitrogen temperature, functioning as an additional cold trap.

\section{Sample transfer into the SEM}

After transportation, the sample boxes were kept in a $-20^{\circ} \mathrm{C}$ cold room. The ice specimen was mounted onto a pretilted aluminium SEM stub $\left(19^{\circ}\right.$ to the horizontal) in the cold room using a drop of water to glue the sample onto the stub. With thicker samples, the temperature difference between the sledge and ice caused localized melting of the ice, which formed a bond. This method was preferred, as the rapid freezing of the water drop makes it difficult to mount samples correctly onto the pretilt stub. The stub was secured in a recess on a cryogenic brass sledge. The transfer protocol described in the following is a modification of techniques developed by biologists and previously applied to low temperature SEM imaging of ice and snow (e.g. Rango et al., 2000; Erbe et al., 2003). The sledge was placed into a plastic tube, which was slowly lowered into a thermos flask containing liquid nitrogen. Submerging the sledge was carried out slowly to reduce thermal shock and so avoid breaking the connection between the ice and the stub. The sample was transported in the thermos flask from the cold room to the microscope room and transferred into a cup containing liquid nitrogen and nitrogen gas atmosphere to prevent the absorption of water (Fig. 2a). The sledge was then screwed onto the transfer rod (Fig. 2b) before evacuating the housing with a rotary pump. Then the sledge was quickly transferred under vacuum $\left(\sim 10^{-4}\right.$ to $\left.10^{-3} \mathrm{hPa}\right)$ to the cryogenic preparation chamber attached to the SEM (Fig. 2c and d). The conditions in the 

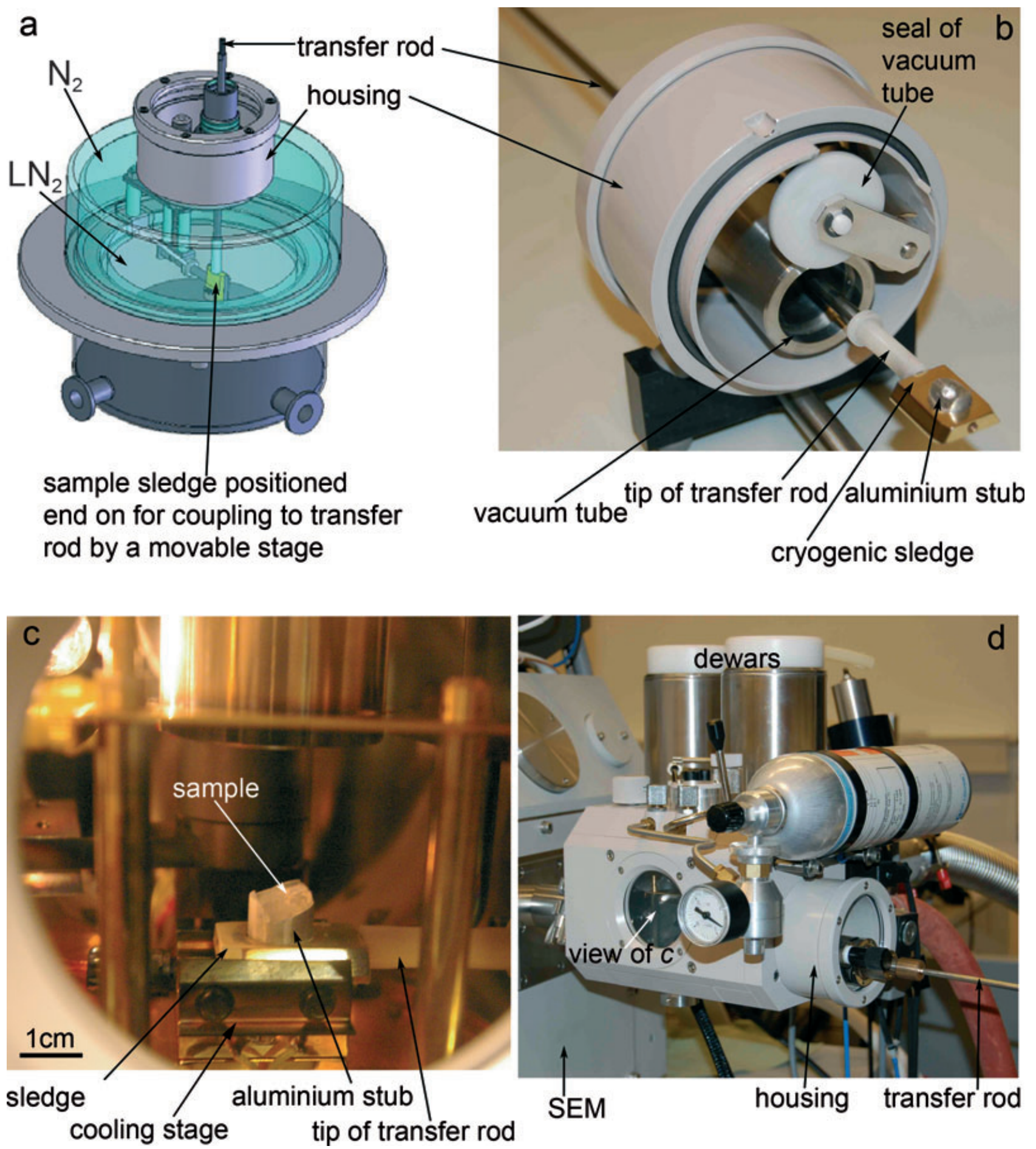

Fig. 2. Images of the cryogenic transfer system and the specimen preparation chamber. (a) Transfer unit $\left(\mathrm{LN}_{2}=\right.$ liquid nitrogen, $\mathrm{N}_{2}=$ nitrogen gas). (b) Transfer rod and sample holder. (c) View through the glass port of the specimen preparation chamber; the sample is mounted on a pretilted aluminium stub which fits into a recess in the cryogenic sledge. (d) External view of the complete Quorum preparation chamber. 


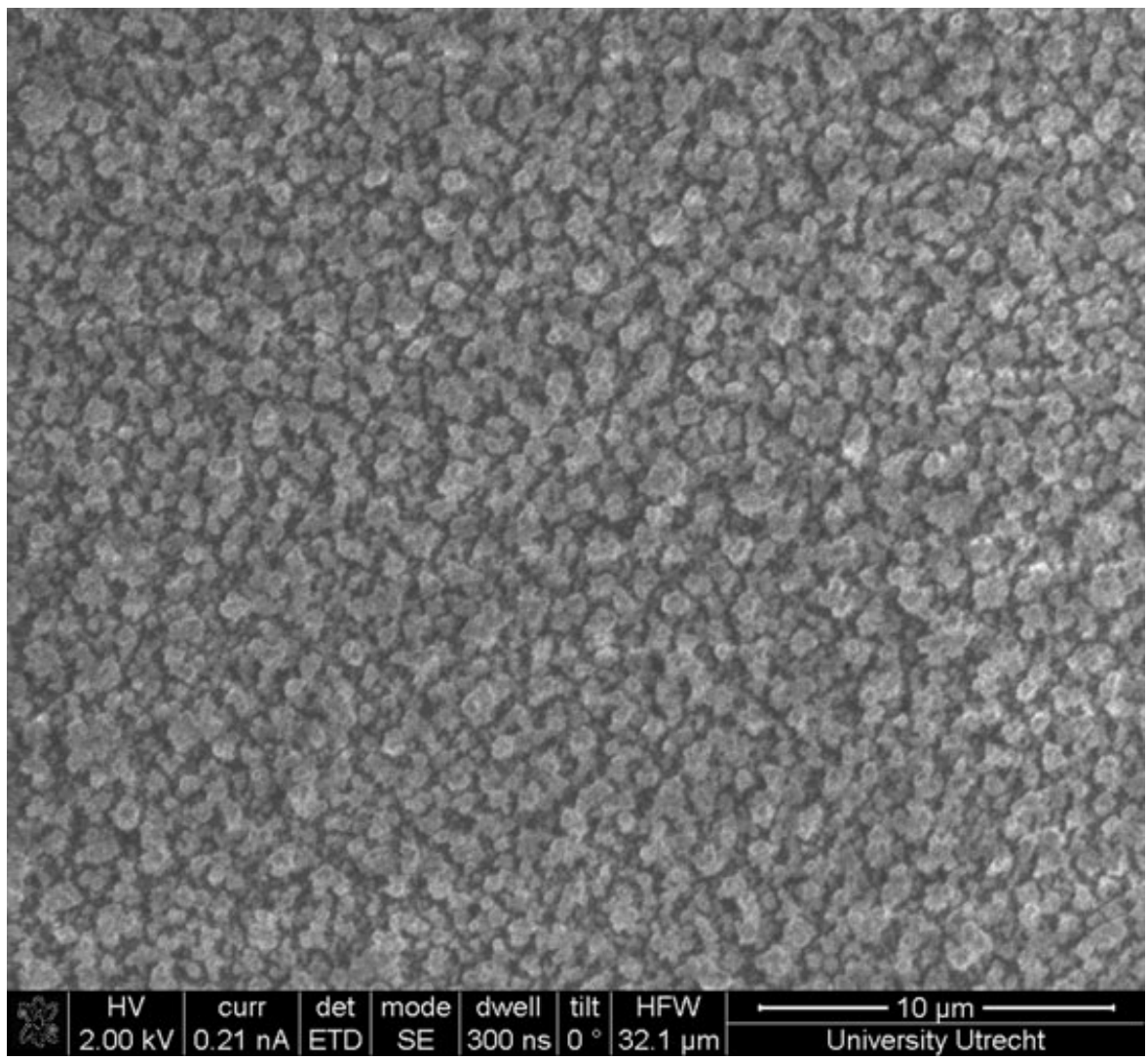

Fig. 3. Surface after sample transfer showing irregular layer of frost crystals with a cauliflower morphology typical for Zone 1 of the structure zone model applied for growth of ice films (Cartwright et al., 2010).

preparation chamber were kept at $10^{-7} \mathrm{hPa}$ and $-186^{\circ} \mathrm{C}$. The transport from cold room to preparation chamber took approximately $5 \mathrm{~min}$. After completing the EBSD analyses the sample was removed via the specimen preparation chamber and discarded.

Controlled sublimation to remove frost. During the transfer process some frost deposition occurred (see Fig. 3). EBSD patterns could not be obtained from the ice surface below the frost. This frost layer was removed by a controlled sublimation step in the preparation chamber by increasing the temperature to $-85^{\circ} \mathrm{C}$ for about $5 \mathrm{~min}$. (Note that the temperature at the surface of the sample took several minutes to equilibrate.) These conditions were based on previous studies (Iliescu et al., 2004) and on in situ observations in the SEM of the change in surface structure during sublimation. Although the sublimation step can be carried out in the SEM microscope chamber, sublimation in the preparation chamber was preferred. This reduced the amount of additional water vapour in the microscope chamber and the subsequent formation of frost onto the specimen surface when working at $-150^{\circ} \mathrm{C}$ was less. Re-deposition of sublimed water vapour also occurred in the specimen preparation chamber when the specimen was cooled down after sublimation $\left(-85^{\circ} \mathrm{C}\right)$ to the stage temperature $\left(<-100^{\circ} \mathrm{C}\right)$. The sample was therefore quickly transferred into the microscope chamber after sublimation without further cooling. A second, shorter sublimation step was sometimes carried out in the specimen preparation chamber to remove frost that developed during prolonged periods of examination at $-150^{\circ} \mathrm{C}$.

\section{SEM conditions}

The SEM pressure and temperature conditions studied in this work are shown in Fig. 4. The stage and cold trap temperatures were independently controlled. Stage temperatures, -103 to $-150^{\circ} \mathrm{C}$, were about $20^{\circ} \mathrm{C}$ warmer than the cold trap. Chamber pressures were typically lower than $2 \times 10^{-6} \mathrm{hPa}$ : higher chamber pressures of $1.4 \times 10^{-5}$ to $1.2 \times 10^{-4} \mathrm{hPa}$ were used to examine the influence of pressure on charging during EBSD mapping. Dry cold nitrogen gas, used to cool the stage, was used to vary the pressure.

The optimum angle for EBSP detection is $70^{\circ}$ towards the horizontal (Randle \& Engler, 2000). Thus together with the preinclination of the holder stub $\left(19^{\circ}\right)$ the stage was tilted by $51^{\circ}$. A pretilt of $19^{\circ}$ optimizes the time needed to reach thermal equilibrium by minimizing the thermal conductivity 


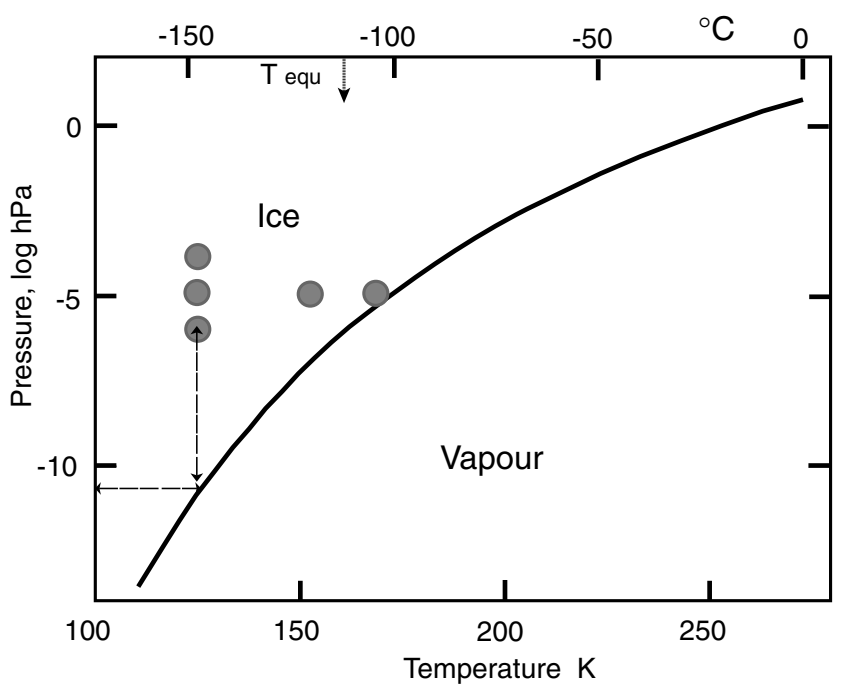

Fig. 4. Ice-vapour phase diagram showing typical SEM chamber pressures and temperature conditions examined in this study (grey circles). The equilibrium temperature, $T_{\text {equ }}$ for a chamber pressure of $1 \times 10^{-6} \mathrm{hPa}$ is shown. The equilibrium partial vapour pressure for a lower stage temperature of $-150^{\circ} \mathrm{C}$ has a much lower pressure than the chamber pressure, and is shown by the dotted line.

path between the sample and the cold stage when the stage is tilted for EBSD. The working distance varied between 5 and 7 $\mathrm{mm}$. The EBSD detector was not fully inserted (about $7.5 \mathrm{~mm}$ distance from the sample) to make sure that the tubes of the cryogenic stage did not touch the detector and to minimize any possible frost deposition onto the sample caused by the close proximity of the uncooled detector. The longer distance between the camera and the sample is less favourable for EBSD indexing, because the solid collection angle is smaller, and less diffraction information is collected. Indexing was nevertheless typically above $80 \%$, although a few grain orientations were poorly indexed: re-analysis of saved patterns, and altering the processing parameters, gave adequate indexing.

Accelerating voltage, beam current, focus and EBSD acquisition parameters were varied to optimize conditions for EBSD mapping using a $30 \mu \mathrm{m}$ aperture. The frame time for EBSP collection was adjusted for each voltage and patterns were averaged twice to 4 -fold. The number of reflectors taken into account for the simulation in the Channel 5 software was 50-80 and the number of bands to be detected varied between 5-6 and 8-9. Typical average cycle time for a measurement during beam mapping varied from 0.1 to $0.2 \mathrm{~s} /$ analysis (5-10 analyses/s).

\section{Results and discussions}

The results from varying pressure and temperature conditions of the SEM, tested in order to minimize sublimation and to retain the etched surface for the duration of the EBSD analyses, are first presented and discussed. The influence of etched surfaces on analysis is presented followed by results on spatial and angular resolution. Finally, EBSD mapped microstructures are compared to LM etched microstructures and first results on subgrain boundary characterization are given.

\section{Sublimation}

Sublimation-condensation related aspects for EBSD in a low pressure SEM. We conducted EBSD mapping for a range of pressure conditions, all of which were carried out at temperatures in the stable ice field (Fig. 4). Under normal high vacuum operating conditions, the chamber pressure is around $1 \times 10^{-6} \mathrm{hPa}$. At a temperature of $-150^{\circ} \mathrm{C}$ ice is in equilibrium with a very low partial water vapour pressure of about $10^{-11} \mathrm{hPa}$ (dotted line in Fig. 4). In our system we used a cold trap, close to the sample surface, which was typically held at $-170^{\circ} \mathrm{C}$; the cold trap is thus in equilibrium with a much lower water vapour pressure than the sample. The close proximity of the cold trap to the sample surface is expected to reduce water deposition and frost formation on the sample; water molecules in the vacuum preferentially deposit onto the colder surface, as evidenced by the noticeable pressure drop in the SEM chamber as the cold trap was cooled. The cold trap effectively functions as a 'cryo-pump' removing water vapour from the chamber, and reducing the water vapour pressure near the sample. Thus the removal of water vapour by the cold trap is expected to lead to some sublimation of the sample (Waller et al., 2008). The cold trap was therefore maintained at about $20^{\circ} \mathrm{C}$ less than the sample.

The sublimation rate of metastable ice in high vacuum SEM instruments operating in the $10^{-6}$ to $10^{-7} \mathrm{hPa}$ range, depends mainly on the temperature (Davy \& Branton, 1970). Sublimation could lead to an increase of chamber pressure, although continuous pumping and the presence of a cold trap will counteract any pressure increase (Cullen \& Baker, 2001). The sublimation rate can be reduced by working at high-pressure conditions in a variable pressure SEM (Waller et al., 2005, 2008). Waller et al. (2005) report that sublimation of ice is noticeable at $-100^{\circ} \mathrm{C}$ in a high vacuum SEM: however, in low vacuum instruments using nitrogen gas, sublimation is only significant above $-75^{\circ} \mathrm{C}$. This suggests that it should be possible to work on stable ice surfaces in the temperature range of -100 to $0^{\circ} \mathrm{C}$ in variable pressure SEMs because usable EBSD patterns can be obtained in variable pressure SEMs up to chamber pressures of around 2-3 hPa (Habesch, 2000).

According to Fig. 4 at $-170^{\circ} \mathrm{C}$ the equilibrium partial vapour pressure of water is below $10^{-15} \mathrm{hPa}$, which is far less than the SEM chamber pressure, which is in the $10^{-7} \mathrm{hPa}$ range. Over a period of several hours, we observed that EBSD patterns deteriorated in maps, which were made at different locations using automatic mapping. When this behaviour occurred, EBSD patterns were observed after several seconds during interactive analysis. We interpret this behaviour as 
being caused by condensation. If so, this implies a partial vapour pressure that is higher than the equilibrium vapour pressure shown in Fig. 4, but must be less than the chamber pressure.

Conditions for reduction of charging effects during EBSD analysis. Due to the low temperatures $\left(<-100^{\circ} \mathrm{C}\right)$ and high vacuums used, sublimation was largely absent; in consequence, localized charge compensation, associated with sublimation (Iliescu et al., 2004) did not occur and EBSD patterns often shifted and degraded during mapping. Improved, stable EBSD patterns were obtained with a slightly defocused beam. Charging behaviour was observed for both a focused and a defocused beam: Fig. 5 compares selected EBSD patterns from maps made in the range $7-20 \mathrm{kV}$ accelerating voltage (beam current from 7.2 to $9.5 \mathrm{nA}$, respectively) and temperatures of -150 to $-100^{\circ} \mathrm{C}$, and chamber pressures between $1.25 \times$ $10^{-4}$ and $1.47 \times 10^{-6} \mathrm{hPa}$. The time per frame increases with a decrease in accelerating voltage and an increase in chamber pressure. EBSD patterns showed the least signs of charging at the highest pressures studied (Fig. 5d) although defocusing gave a small improvement in pattern quality and a better percentage of indexed patterns. However, analysis times were much longer at higher pressures. Under normal low pressure conditions (no nitrogen gas) operating at $-150^{\circ} \mathrm{C}$ minimized sublimation (Fig. 5e-h) but with a focused beam charging occurred and patterns were poor: as before, defocusing the beam improved patterns. Defocus was determined from the difference in working distance. The amount of defocus tended to increase with accelerating voltage so mapping at lower voltages $(10 \mathrm{kV})$ was preferred, although the analysis time (time per frame) to collect patterns increased with lower accelerating voltages.

Defocusing also improved the quality of the mapped grid (Fig. 6): a grid of damage spots, caused by the electron beam, was often visible on the surface after mapping. The grid gave a direct indication of the beam deflection during mapping. We observed grids close to regular squares with a defocused beam (Fig. 6b), whereas drift of the primary electron beam, caused by charging, occurred when the beam was focused on the surface (Fig. 6a). This deflection causes a distortion in the mapped grid microstructure. As a square mapped grid is important for a good correlation of LM and EBSD mapped microstructures a defocused beam was preferred. Alternative to defocusing the beam, a selected area scan can be used and orientations can be collected at manually selected locations, although mapping microstructures is no longer possible.

\section{Etched and sublimed surfaces}

Locating the region of interest in the SEM. The etching procedure for LM microstructure mapping preferentially removed material from boundary regions forming grooves that are also visible using secondary electrons (SE). It was

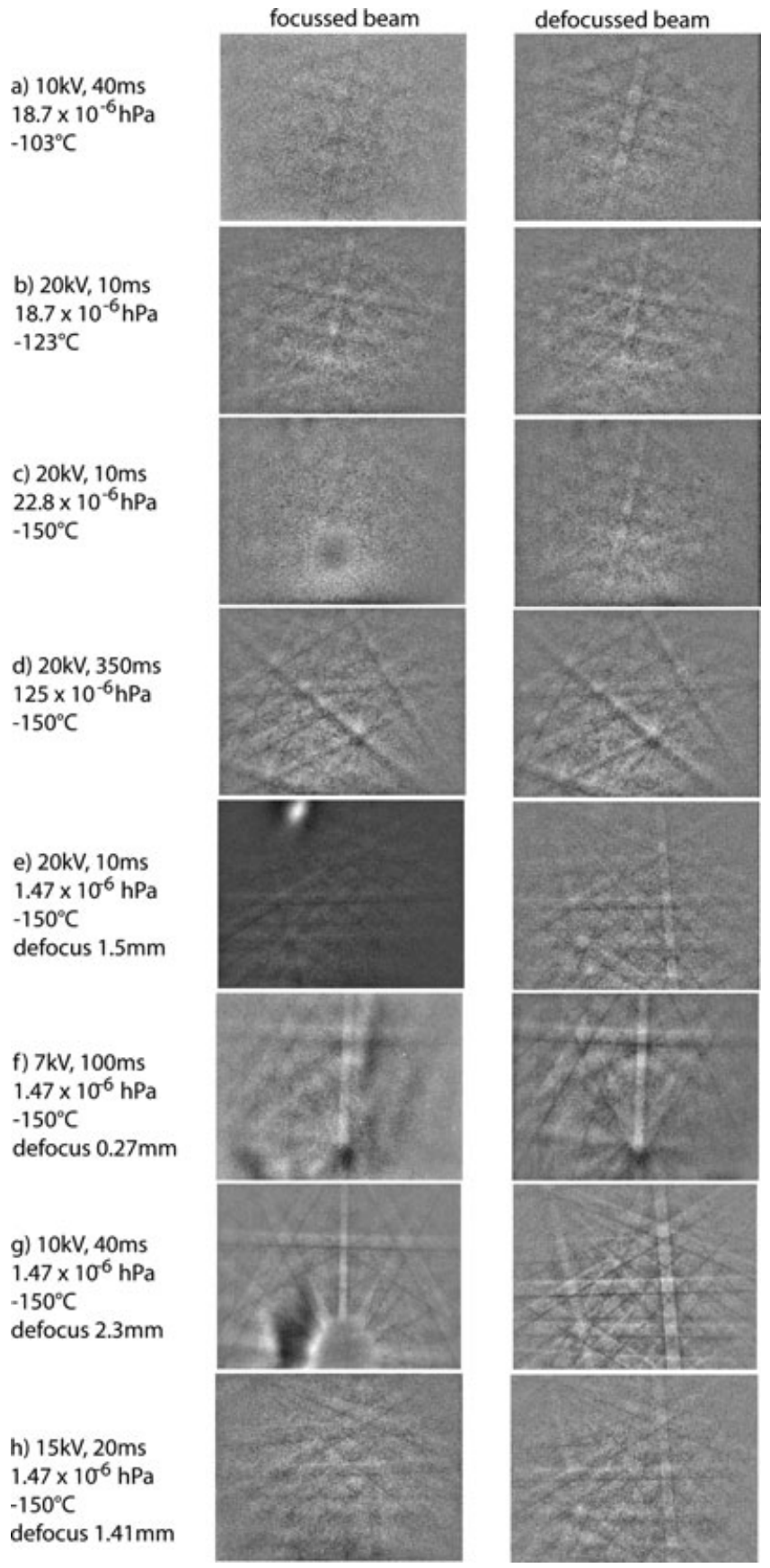

Fig. 5. Comparison of EBSD patterns with focused and defocused beam for different chamber pressures. (a)-(d) High pressure conditions using nitrogen gas. (e)-(h) Low pressure conditions. Accelerating voltage in $\mathrm{kV}$, time per frame for EBSD pattern collection in msec, chamber pressure in $\mathrm{hPa}$ and temperature in ${ }^{\circ} \mathrm{C}$. Maps were made on regions that had not previously been mapped: step size $5 \mu \mathrm{m}$, grid size $10 \times 10$. Values for defocus, where noted, are given in $\mathrm{mm}$. 

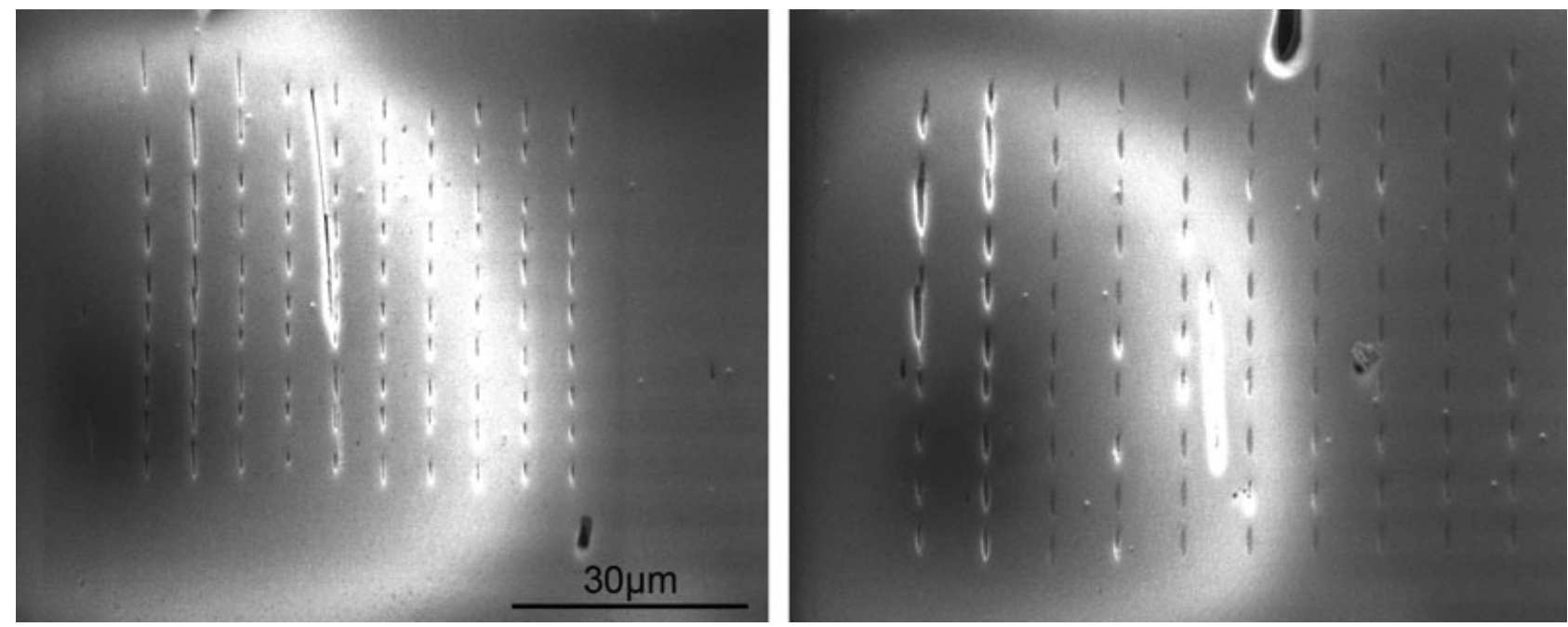

Fig. 6. Example of grid of damage spots, caused by the electron beam (a) in focus and (b) out of focus. Apart from focus, EBSD map settings are identical (10 kV accelerating voltage, $40 \mathrm{~ms}$ per frame for EBSD pattern collection, $1.4 \times 10^{-5} \mathrm{hPa}$ chamber pressure, $-103^{\circ} \mathrm{C}$ chamber temperature). Distortion of grid is significantly less in (b) when the beam is out of focus. Note, the $5 \mu \mathrm{m}$ step size as set in the mapping software is actually slightly changed when using a defocused beam giving a slightly larger spot distance in (b). The accurate resolution and scale for maps has to be determined from an SE image taken after the mapping.

therefore possible to locate the regions of interest from the deeper etched grooves at grain boundaries in the SEM at the lowest magnifications (Fig. 7). Any changes in the position of boundaries in the etched surface structures that occurred during transfer and storage were documented by comparison of LM and SE images. In this region, one boundary has altered position during the period between microstructure mapping and SE imaging (Fig 7b). However, bearing in mind that naturally occurring ice is at a high homologous temperature $\left(T_{\mathrm{m}} \sim 0.9\right.$ in natural settings and standard storing conditions, and $T_{\mathrm{m}} \sim 0.74$ in dry ice storage) the changes are slight. It is known from relaxation annealing experiments with polar
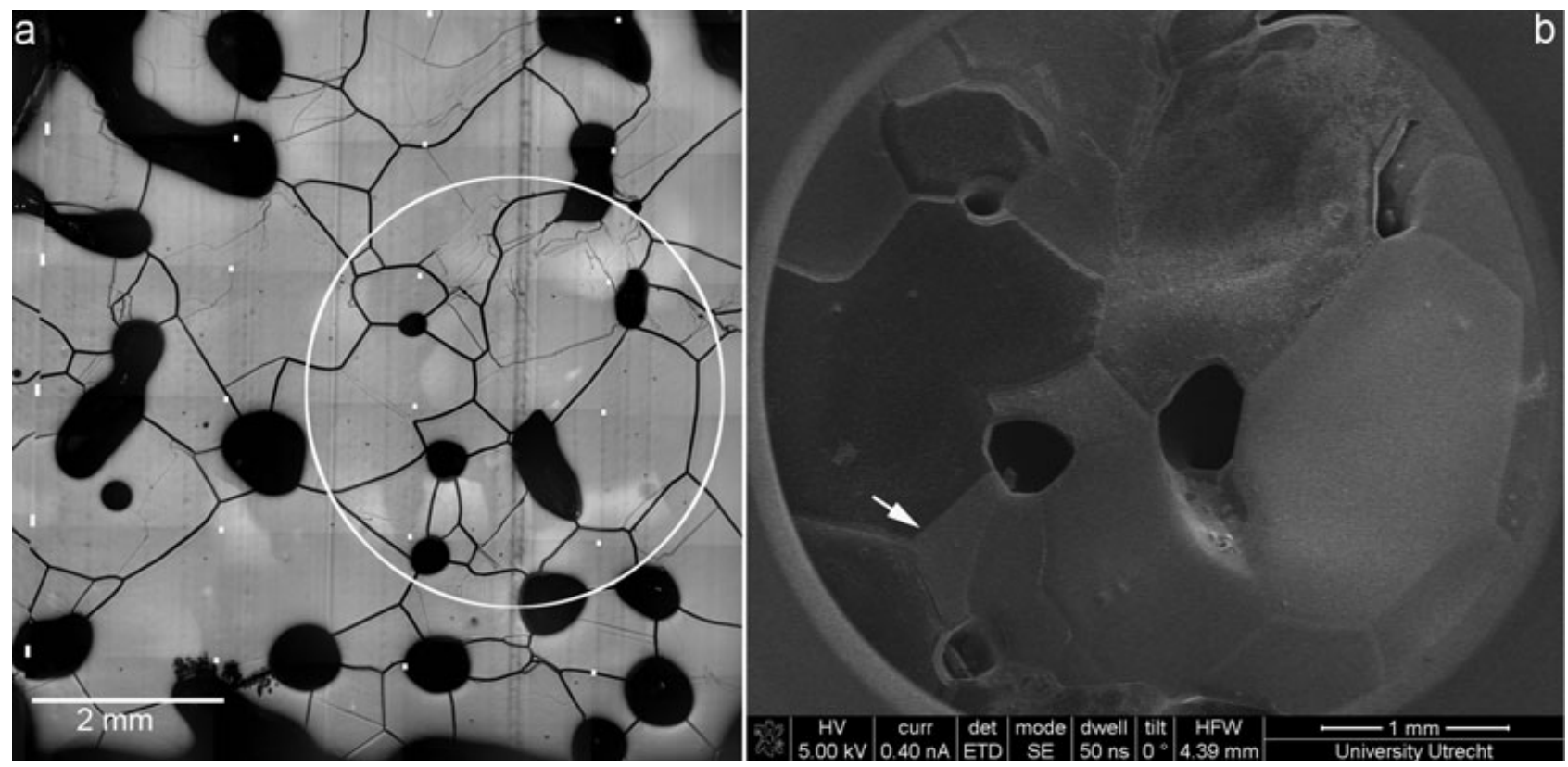

Fig. 7. Locating the region of interest in the SEM. Surface features after sublimation etching in Bremerhaven showing boundary and pore features (core B37, $93.9 \mathrm{~m}$ depth). (a) LM microstructure mapping image. (b) SE image of the corresponding area indicated as white circle in (a) before sublimation to remove frost in the SEM: The field of view in the SEM is restricted by the final lens aperture; grain boundaries and pores are visible which allows location of the region of interest. Most grains have the same shape: one boundary (arrowed) has altered position. 

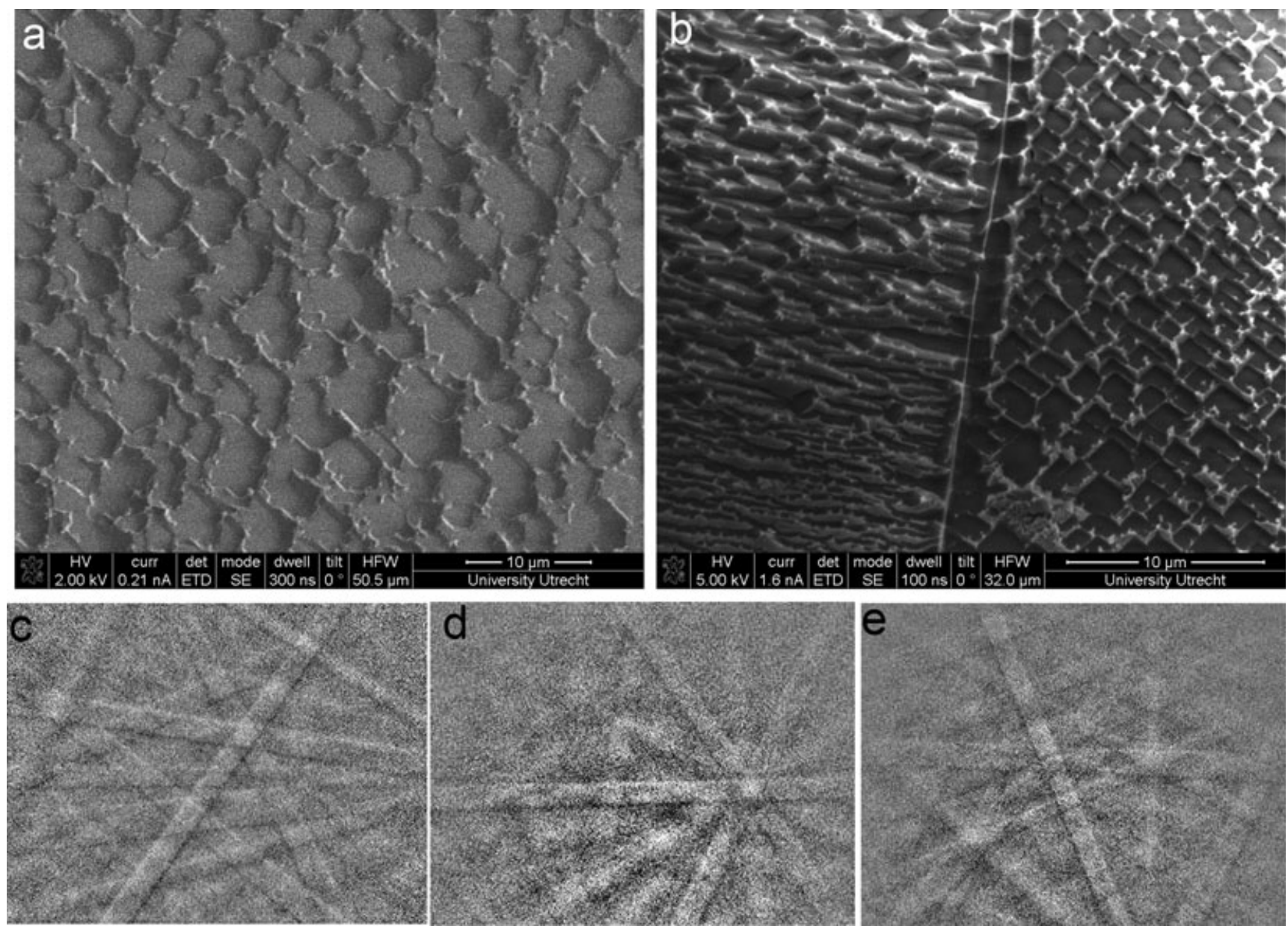

Fig. 8. Effect of sublimation on surface and EBSD patterns. (a) Rough facetted surface produced after sublimation (sample EDML $1735.9 \mathrm{~m}$ depth). (b) The variation in facet surface across a grain boundary on a sublimed surface depending on crystal orientation (sample EDML $2385.9 \mathrm{~m}$ depth). (c) EBSP from sample in (a). (d) EBSP from left grain in (b) (e) EBSP from right grain in (b).

ice samples, in which polished sections were periodically mapped using LM (Kipfstuhl et al., 2006) and also from creep tests on artificial ice (Hamann et al., 2007) that the typical position and geometry of subgrain boundaries do not alter, whereas curved grain boundaries usually move, probably due to their oblique intersection with the freshly cut surface. Despite the measures taken to protect the surfaces between LM microstructure mapping and SE imaging, some space above the sample surface is needed in order to avoid damage to the polished sample surface, so minor changes in microstructures may have been related to sublimation during transport and storage. Nevertheless, these minor changes do not alter the main characteristics of the microstructure, that is, the preservation and general arrangement of subgrain boundary microstructures.

EBSD patterns and sublimed surfaces. The surface before sublimation in the preparation chamber shows a frost layer (Fig. 3). Rough, facetted surfaces developed after this sublimation step (Fig. 8a and b), which are typical of sublimation features (Cross, 1969; Cullen \& Baker, 2001). The pattern of roughness depends on the crystal orientation (Fig. 8b). Good EBSPs were obtained from these facetted surfaces (Fig. 8c-e), which are 1-2 orders of magnitude smaller than those reported previously (see for example fig. 1 in Cullen \& Baker, 2001).

Influence of etch grooves on EBSD data. Although etching was necessary to identify the boundary types and to locate regions of interest in the SEM, etching created grooves. Some subgrain boundary information might be lost in the etching process, particularly in regions adjacent to grain boundaries. Also, patterns in the regions of deeper grain boundary grooves were often poor, or poorly indexed (Fig. 9a). As subgrain boundaries generally accumulate close to the grain rim (Weikusat et al., 2009a) the width of the grain boundary groove is important: Fig. 8(b) shows a typical grain boundary groove, which is 1-2 $\mu \mathrm{m}$ wide and preliminary results from atomic force microscopy suggest that the depth is much less (Rüdiger Berger, 2006, personal communication). As the subgrain structures of 


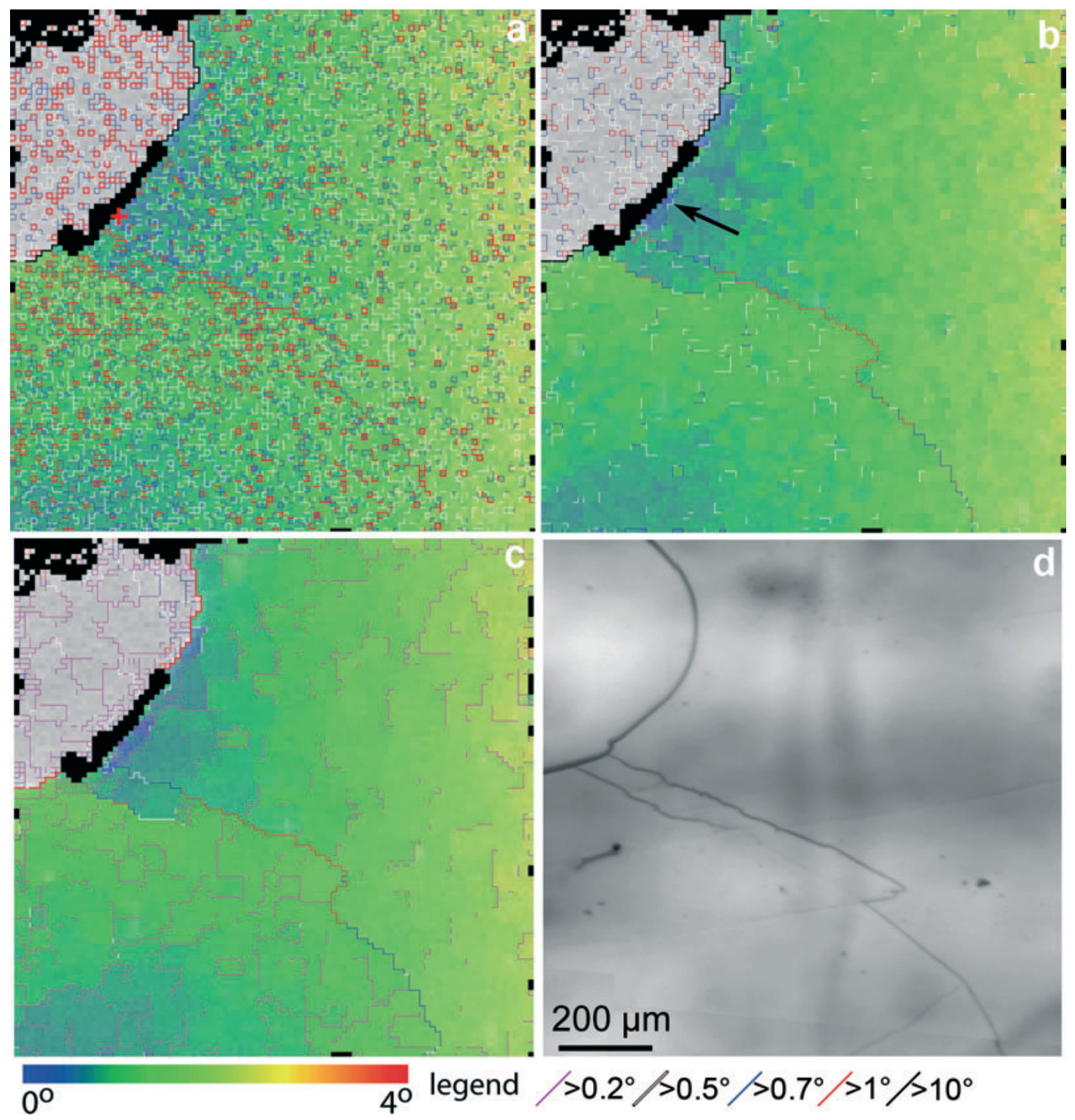

Fig. 9. EBSD and LM mapped microstructure. (a) Large area EBSD map after replacement of some nonindexed pixels and all misindexed pixels (step size $10 \mu \mathrm{m}, 10 \mathrm{kV}$ acceleration voltage, $-150^{\circ} \mathrm{C}$ ). Etched grain boundaries are poorly indexed. Lower grain shows a slight orientation gradient, as indicated by the change in colour relative to the red cross (see legend). (b) After orientation averaging (two passes of a $3 \times 3$ filter) most of the low angle noise is removed to show subgrain boundaries penetrating several hundreds of $\mu \mathrm{m}$ into the core of the grain. Filtering removes most of the low angle misorientation noise but also creates a low angle boundary artefact, shown by the arrow. (c) After orientation averaging (two passes of a $5 \times 5$ filter) boundaries with very low angle misorientations (pink lines) are also artefacts of the orientations averaging filter. Angular resolution is about $0.7^{\circ}$ after orientation averaging. (d) Corresponding etched microstructure, reflected LM. Correlation with EBSD microstructure is excellent. 

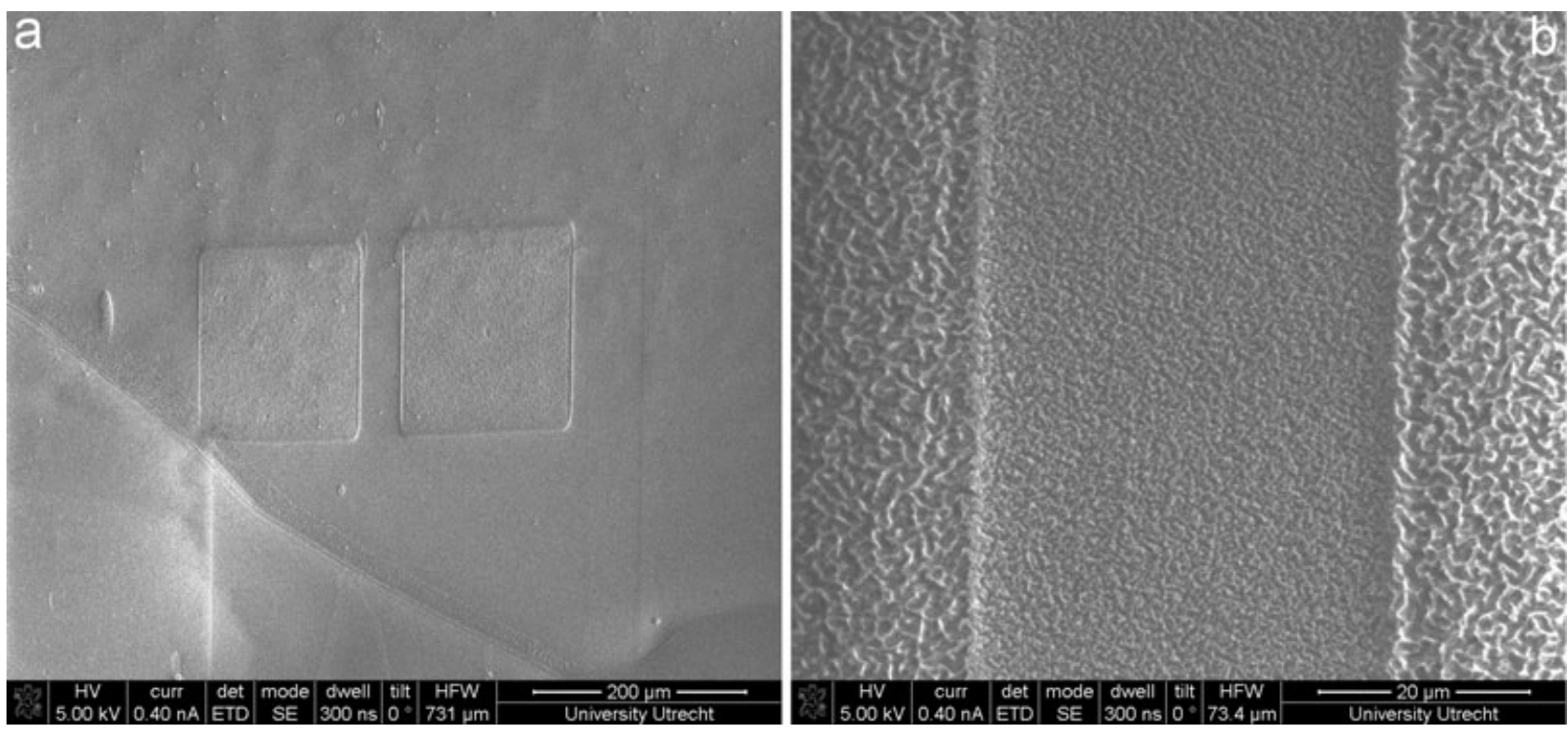

Fig. 10. Influence of beam exposure to surface topography. Sample was given a second sublimation $\left(5 \mathrm{~min}\right.$ at $-85^{\circ} \mathrm{C}$ ) after scanning the area. a: Areas exposed to the electron beam clearly stand out as squares (left: $20 \mathrm{~min}$ at $10 \mathrm{kV}$, right: $30 \mathrm{~min}$ at $10 \mathrm{kV}$ ). (b) Detail of (a) showing the preexposed areas (left and right) and the sublimed surface (band in the middle) which was not exposed to the electron beam.

interest are of the order of $10 \mu \mathrm{m}$ apart and penetrate by at least several hundreds of microns into the core of the grain (see Fig. 9b) the etch grooves are not expected to prevent the observation of subgrain boundaries and characterization of slip.

Influence of electron beam radiation and sublimation history on EBSD patterns. We found that exposure to the electron beam influenced sublimation and frost deposition behaviour, both during and after imaging. When sublimation was performed in the microscope chamber, a reduction in EBSP quality was observed with time. After several hours of analysis and at the lowest temperatures $\left(-150^{\circ} \mathrm{C}\right)$, a delay time of up to $20 \mathrm{~s}$ was observed before EBSD patterns became visible, possibly due to sublimed water slowly re-depositing onto the specimen surface. However, EBSD patterns appeared immediately in locations that had previously been exposed to the electron beam. This behaviour was reversed after a subsequent second sublimation: preexposed areas yielded hardly any patterns and showed an altered surface (Fig. 10) in contrast to surrounding areas. This structure differs to the sublimation facets shown in Fig. 8. Thus, the immediate appearance of patterns on preirradiated areas is likely to be caused by locally enhanced sublimation and not surface roughness, whereas this may be the cause for the difficulties in obtaining patterns after re-subliming a preirradiated area. Water molecules from the vapour during sublimation are attracted to areas with a small local charge, enhancing condensation locally. The rate of frost deposition would be higher in the imaged areas, resulting in worse EBSD patterns.
Stability of sample surface. We assume that the surfaces examined under conditions shown in Fig. 4 are stable. To test the stability of the surface, two maps of the same area that were made over a period of 4-5 $\mathrm{h}$ were compared (Fig. 11). No evidence for a change in orientation was found in the maps. However, the orientation gradients in ice samples (see Section 'Angular resolution' and Fig. 9) are slight (2.5 over $800 \mu \mathrm{m}$ ) so several hundred microns of material would need to be sublimed to determine any evidence of a change in orientation. However, the indexing rate for both maps was approximately the same $(87 \%)$, which suggests that no significant re-deposition of sublimed water vapour back on to the surface occurred.

\section{Resolution}

Spatial resolution. In order to determine the spatial resolution as a function of chamber pressure, temperature and defocus, small step size line scans were made over vertical grain boundaries perpendicular to the scan direction (Humphreys et al., 1999). Care was taken to use boundaries that did not show grain boundary ridges (Barnes, 2003). Fig. 12 shows examples of sequential EBSD patterns taken using a defocused beam, at $10 \mathrm{kV}$ for high and low pressure conditions and at two temperatures. For higher pressure and temperatures $\left(1.1 \times 10^{-5} \mathrm{hPa},-123^{\circ} \mathrm{C}\right)$ only a slight defocus was necessary to compensate charging: two patterns taken with a step of $0.25 \mu \mathrm{m}$, which border the grain boundary, exhibit bands from both grains (Fig. 12a) giving a spatial resolution of 

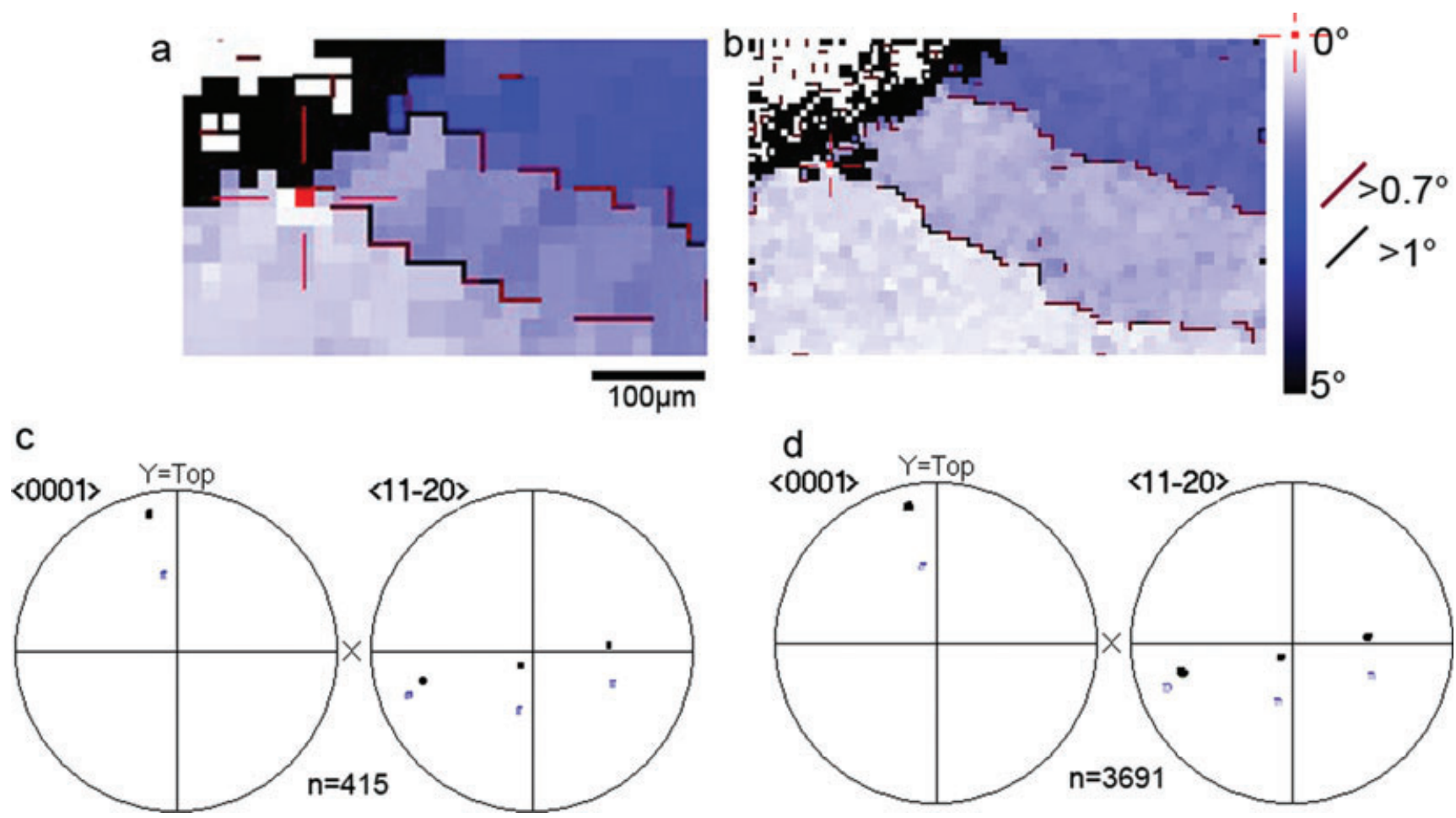

Fig. 11. EBSD maps showing reproducibility of (sample EDML $2575.8 \mathrm{~m}$ depth). (a) EBSD map (step size $10 \mu \mathrm{m}$ ) (b) second EBSD map of the same area (step size $1 \mu \mathrm{m}$ ). Indexing was $87 \%$ and $88 \%$ respectively (without offline reanalysis). (c) Stereographic projection (upper hemisphere) of data ( $n$ : number of data points) in (a). (d) Stereographic projection (upper hemisphere) of data in (b). Colour shows changes in orientation and grain boundary misorientations given in the legend. Accelerating voltage $10 \mathrm{kV}$. Noise reduction of both maps was made by replacement of some nonindexed pixels and all misindexed pixels and one pass of a $3 \times 3$ modified Kuwahara filter.
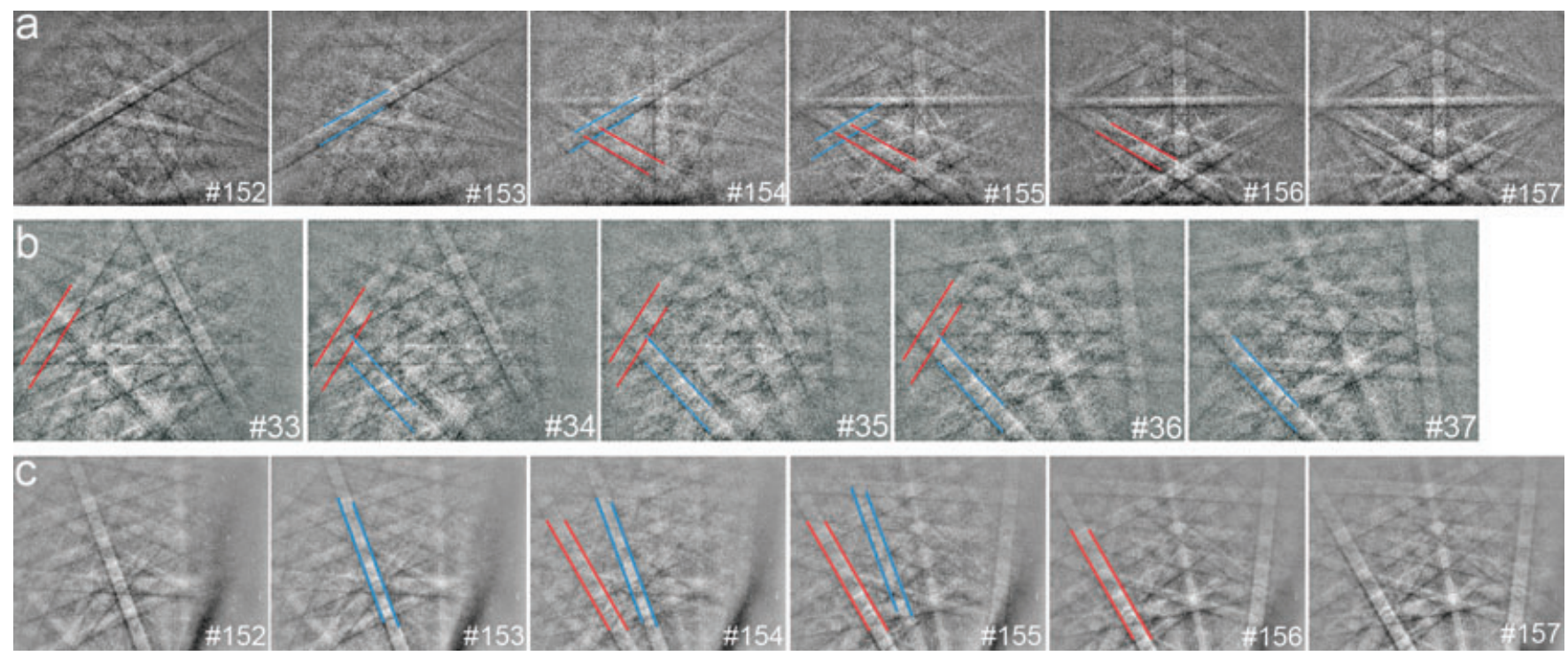

Fig. 12. Sequential EBSPs across vertical grain boundaries obtained using a horizontal beam scan and a slightly defocused beam. (a) High pressure $\left(1.1 \times 10^{-5} \mathrm{hPa}\right)$ at $-123^{\circ} \mathrm{C}$ and $10 \mathrm{kV}$ with step size $0.25 \mu \mathrm{m}$. Two images (\#154-155) show bands from both patterns of neighbouring grains. (b) Low pressure $\left(1.3 \times 10^{-6} \mathrm{hPa}\right)$ at $-150^{\circ} \mathrm{C}$ and $10 \mathrm{kV}$ with step size $1 \mu \mathrm{m}$. Three images (\#34-36) show bands from both patterns of neighbouring grains. (c) Low pressure $\left(6.7 \times 10^{-7} \mathrm{hPa}\right)$ at $-120^{\circ} \mathrm{C}$ and $10 \mathrm{kV}$ with step size $0.25 \mu \mathrm{m}$. Three images (\#154-155) show bands from both patterns of neighbouring grains. Spatial resolutions are $0.5,3$ and $0.5 \mu \mathrm{m}$, respectively. 
$\sim 0.5 \mu \mathrm{m}$ in the $x$-direction. At lower pressures and temperatures $\left(1.3 \times 10^{-6} \mathrm{hPa},-150^{\circ} \mathrm{C}\right)$ a much larger defocus was needed to compensate charging: double patterns were observed in three consecutive $1 \mu \mathrm{m}$ steps across a boundary, giving a spatial resolution of $3 \mu \mathrm{m}$ (Fig. 12b). Low pressures and higher temperatures $\left(6.7 \times 10^{-7} \mathrm{hPa},-120^{\circ} \mathrm{C}\right)$ are shown in Fig. 12(c): double patterns were observed in two consecutive $0.25 \mu \mathrm{m}$ steps across the boundary, giving a spatial resolution of $\sim 0.5 \mu \mathrm{m}$. Of importance is, that the patterns using a defocused beam under low-pressure conditions are still of good quality. The patterns were stable even at step sizes down to $0.25 \mu \mathrm{m}$, except for a slight saturation due to charging as the beam crossed the grain boundary. The effective resolution in the $x$-direction, as defined by the successful analysis of patterns by the software, may be better than shown in Fig. 12 (Humphreys et al., 1999; Humphreys, 2001).

These results show that spatial resolution is better with higher pressures. If high pressures are available, EBSD data can be collected with a focused beam using nitrogen gas to compensate charging (Waller et al., 2008). This is shown for example in Fig. 5(d) for pressures of $1 \times 10^{-4} \mathrm{hPa}$, but analysis times are very long. Alternatively, if stable surfaces are not needed, better spatial resolutions can be obtained, at low pressures, with a focused beam and operating at higher temperatures, $>-100^{\circ} \mathrm{C}$, so that slow sublimation compensates charging. In our work we have found that operating at temperatures of about $-120^{\circ} \mathrm{C}$ gives reasonably stable surfaces for EBSD mapping over long time periods and good spatial resolution under low pressure conditions of about $1 \times 10^{-6} \mathrm{hPa}$. If extremely limited sublimation is needed, working at much lower temperatures $\left(-150^{\circ} \mathrm{C}\right)$ is possible with a larger defocus.

Attempts to measure the spatial resolution in the $y$-direction were hampered because of the slower scan times, which caused the sample to charge more than during measurements in the $x$-direction. Spatial resolution in the $y$-direction is expected to be three times the $x$-value because of the high sample tilt (Humphreys, 2004).

The finest substructure separation observed in LM microstructure mapping were of the order of $10 \mu \mathrm{m}$, and the spatial resolution for low pressure and very low temperature operation with a defocused beam is $\sim 3 \mu \mathrm{m}$. Thus, most substructures are detected. Hence the lower spatial resolution caused by using a defocused beam to compensate for charging when operating in high vacuum conditions, is not a limitation in the characterization of subgrain boundaries in etched surfaces of naturally deformed polar ice. To cover large areas and depth ranges for conclusions on ice sheet flow, future EBSD measurements on coarse grain ice core samples might need to compromise on resolutions for a quick data collection.

Angular resolution. Maps of up to several square millimeters were mapped over periods of up to several hours using large step sizes $(5-15 \mu \mathrm{m})$. The maps showed no evidence of distortions providing areas around pores were avoided. Fig. 9 shows a typical result of an area containing two grains and a few subgrains. Fig. 9(a) shows the mapped data after replacing some nonindexed pixels and a few misindexed pixels. Many pixels have misorientation angles of $0.5^{\circ}-2^{\circ}$, which is the limit of angular resolution for the unprocessed data in this map. The traces of subgrain boundaries shown in LM microstructure mapping (Fig. 9d) are difficult to discern from the background noise (Fig. 9a). The angular resolution can be improved by orientation averaging using a modified Kuwahara filter; however, for microstructures showing a continuous orientation gradient, the filter should only be used if an independent technique, such as the highly sensitive etched microstructures (Weikusat et al., 2010), can be used to check the nature of the microstructure (Humphreys et al., 2001; Hurley \& Humphreys, 2002). As there is a slight orientation gradient in the lower grain, about $2.5^{\circ}$ over 80 pixels $(800 \mu \mathrm{m})$, some care is needed in interpreting orientation averaged data. Fig. 9(b) shows mapped data after orientation averaging using a $3 \times 3$ filter. The angular resolution in this map after orientation averaging is at least $0.7^{\circ}$. However, a low misorientation artefact boundary, $0.5^{\circ}-$ $1^{\circ}$, has been created between a few pixels near to the grain boundary (arrowed), which is not visible in raw data or in the etched microstructure (Fig. 9d). Using a larger size, $5 \times 5$ filter, produces a map with a slightly better angular resolution of about $0.5^{\circ}$ (Fig. 9c), but creates additional artefacts, in the form of islands of similar orientations that are surrounded by very low angle misorientations, $<0.2^{\circ}-$ $0.5^{\circ}$. These have slightly higher misorientation angles than the artefact islands described by Humphreys et al. (2001) which had misorientations $\sim 0.1^{\circ}$. Orientation averaging could possibly also affect the misorientation axis precision by reducing the spread of data, because the method filters out noise.

\section{Correlation between EBSD and LM mapped microstructures}

The EBSD (Fig. 9a-c) and LM mapped microstructures (Fig. 9d) show slightly different kink geometry of the subgrain boundary. The EBSD mapped surface (Fig. 9c) is possibly slightly deeper in the $z$-direction compared to the LM micrograph (Fig. 9d). A difference in z-direction could cause small differences in the lengths and positions of boundaries in the two images. Mounting the sample for EBSD mapping can also produce some variation in the surface tilt compared to the LM images taken on untilted samples (for instance, when fixing the sample to the SEM holder). Despite these minor limitations, the correlation between the mapped microstructure and the etched microstructure is very good, even after analysing the sample for several hours in the SEM ( $4 \mathrm{~h}$ for Fig. 9).

To summarize, we have found that a stable ice surface, in which sublimation is reduced and etch surfaces are retained 

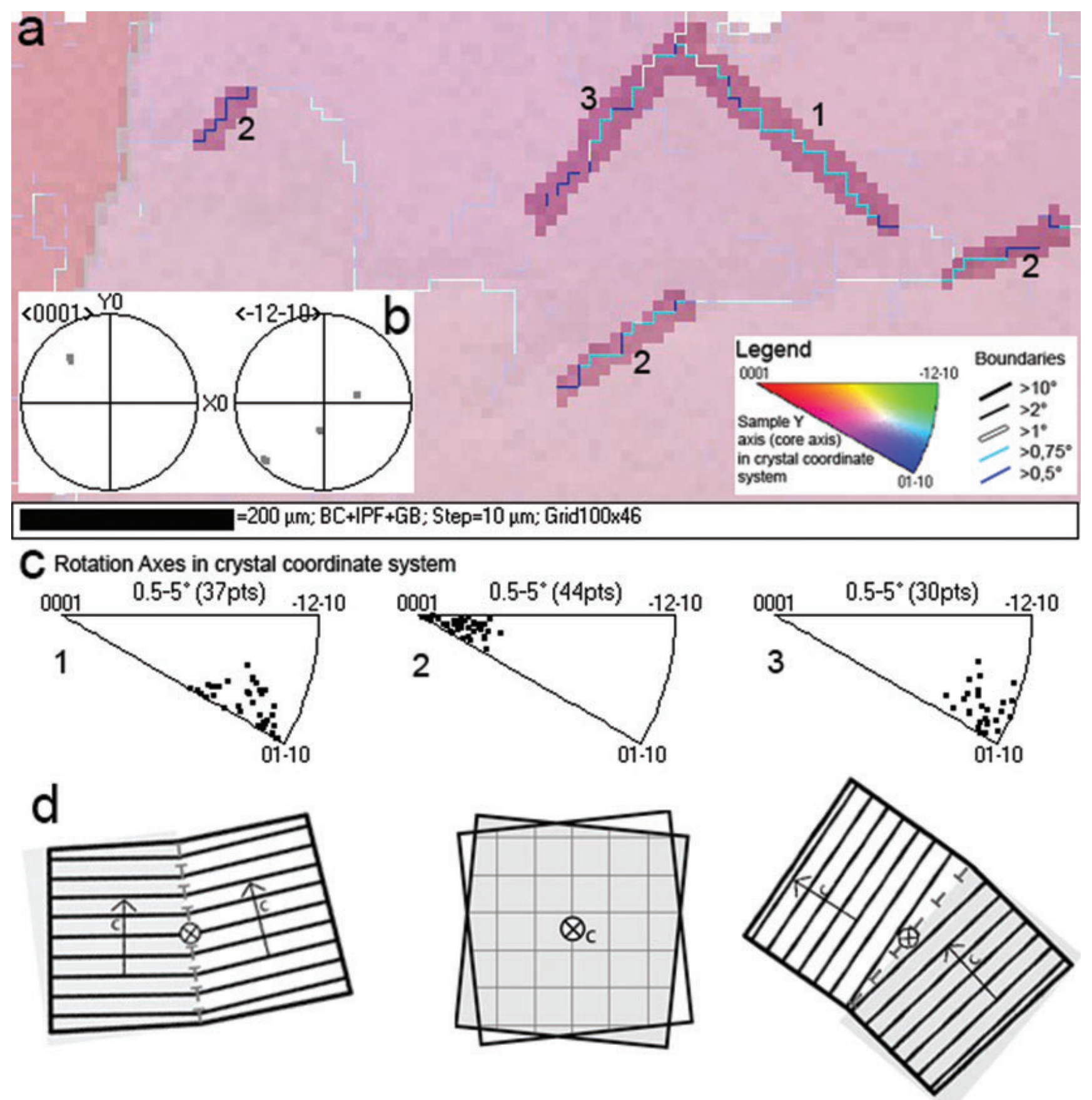

Fig. 13. EBSD analysis from EDML sample $655.9 \mathrm{~m}$ depth. (a) Map with subsets along subgrain boundaries highlighted. Subgrain boundary types are labelled 1-3. (b) Stereographic projections of $c$ - and $a$-axes. (c) Rotation axes among neighbouring pixels with misorientation $>0.5^{\circ}$ in the subgrain boundary subsets. Labels 1-3 correspond to labels in (a). (d) Simplified interpretation following Weikusat et al. (2010) showing the existence of (1) tilt boundaries comprised of edge dislocations gliding in the basal plane, (2) twist boundaries built by basal screw dislocation sets and (3) tilt boundaries comprised of edge dislocations gliding in nonbasal planes.

for the duration of the EBSD analyses, is obtained by working at lower temperatures in a low pressure SEM. Under these conditions EBSD mapping is best carried out using a defocused beam. Although spatial resolution is reduced with a defocused beam, microstructures of interest can be resolved.
Subgrain boundaries in polar ice samples classified by EBSD

Using EBSD analysis, different subgrain boundaries can be classified (Fig. 13). Subgrain boundaries of parallel arrangements with the basal plane (label 3 and 2 in Fig 13a) 
or normal orientation with the basal plane (label 1 in Fig 13a) have been preselected by LM and analyzed by EBSD. Taking into account the high plastic anisotropy of ice (slip mainly on the basal plane), this arrangement and the rotation axes (Fig. 13c) can be used to deduce the generic boundary type (Weikusat et al., 2010). This example shows the existence of (1) tilt boundaries comprised of edge dislocations with burgers vector lying in the basal plane, (2) twist boundaries built by basal screw dislocation sets and (3) tilt boundaries comprised of edge dislocations gliding in nonbasal planes. The latter was indeed not expected due to the high preference of basal glide and will thus be subject of further investigations. In order to deduce the relevance of these dislocation walls for the ice sheet flow a rather large amount of EBSD analysis is needed over several depth ranges along the ice core. As we pointed out before it is demanding to deal with substructure data from large grain sizes observed in natural ice. Rapid data collection of good quality EBSD maps is important to minimize the time needed for measurements and data processing to obtain significant statistics for conclusions on large scale ice sheet flow.

\section{Conclusions}

We present a method for cryogenic EBSD analyses applied to naturally deformed polar ice samples, which retains a stable sample surface during data acquisition in a low pressure SEM $\left(<2 \times 10^{-6} \mathrm{hPa}\right)$. A stable surface allows the combination of high-resolution LM microstructure mapping and EBSD mapping of subgrain boundaries required to characterize deformation microstructures along a $3 \mathrm{~km}$ ice core. Samples were kept at very low temperatures, $<-100^{\circ} \mathrm{C}$, to limit sublimation. Defocusing the beam prevented charging and reduced distortion in EBSD mapped microstructures. Spatial resolution depended on pressure. For low pressures $(<1 \times$ $10^{-6} \mathrm{hPa}$ ) it was about $3 \mu \mathrm{m}$ in the $x$-direction at $-150^{\circ} \mathrm{C}$ and $0.5 \mu \mathrm{m}$ at $-120^{\circ} \mathrm{C}$ with a defocused beam. Misorientations of $>0.7^{\circ}$ were resolved in mapped microstructures. The microstructure of EBSD data had adequate spatial and angular resolution and was consistent with LM mapped features. The microstructure of low misorientation subgrain boundaries mapped using EBSD could be correlated with microstructural detail in large area, etched surfaces, that were previously characterized using high resolution etched LM in natural polar ice samples. First results on boundary type characterization by EBSD data revealed subgrain boundaries with basal (tilt and twist boundaries) and nonbasal dislocations (tilt boundaries).

\section{Acknowledgements}

This project was funded by the German Science Foundation (DFG HA 5675/1-1 and WE 4695/1-2). This work is a contribution to the European Project for Ice Coring in Antarctica (EPICA), a joint European Science
Foundation/European Commission scientific programme, funded by the EU and by national contributions from Belgium, Denmark, France, Germany, Italy, the Netherlands, Norway, Sweden, Switzerland and the United Kingdom. The main logistic support was provided by IPEV and PNRA (at Dome C) and AWI (at Dronning Maud Land). This is EPICA publication no. 271. The FIB-SEM microscope at University Utrecht is funded by NWO Groot and FEI.

\section{References}

Alley, R.B., Gow, A. \& Meese, D. (1995) Mapping c-axis fabrics to study physical processes in ice. J. Glaciol. 41, 197-203.

Andreas, E.L. (2007) New estimates for the sublimation rate for ice on the Moon. Icarus 186, 24-30.

Baker, I., Obbard, R., Iliescu, D. \& Meese, D. (2007) Microstructural characterization of firn. Hydrol. Process. 21, 1624-1629.

Barnes, P.R.F. (2003) Comment on "Grain boundary ridge on sintered bonds between ice crystals”[ J. Appl. Phys. 90, 5782 (2001) ]J. Appl. Phys. 93, 783-785.

Barnes, P.R.F., Mulvaney, R., Wolff, E.W. \& Robinson, K. (2002) A technique for the examination of polar ice using the scanning electron microscope. J. Microsc. 205(2), 118-124.

Bindoff, N., Willebrand, J., Artale, V., et al. (2007). Observations: oceanic climate change and sea level. Climate Change (2007): the Physical Science Basis. Contribution of Working Group I to the Fourth Assessment Report of the Intergovernmental Panel on Climate Change (ed. by Solomon, S., Qin, D., Manning, M., Chen, Z., Marquis, M., Averyt, K., Tignor, M. \& Miller, H.), pp. 385-432. Cambridge University Press, Cambridge, United Kingdom and New York, NY, USA.

Cartwright, J.H., Escribano, B. \& Sainz-Diaz, C.I. (2010) Ice films follow structure zone model morphologies. Thin Solid Films, 518, 3422-3427.

Cross, J.D. (1969) Scanning electron microscopy of evaporating ice. Sci., New Ser. 164(3876), 174-175.

Cullen, D. \& Baker, I. (2001) Observation of Impurities in Ice. Microsc. Res. Technol. 55, 198-207.

Davy, J.G. \& Branton, D. (1970) Subliming ice surfaces: freeze-etch electron microscopy. Science 168(3936), 1216-1218.

de Meer, S., Drury, M.R., De Bresser, J.H.P. \& Pennock, G.M. (2002) Current issues and new developments in deformation mechanisms, rheology and tectonics. Deformation Mechanisms, Rheology and Tectonics: Current Status and Future Perspectives (ed. by de Meer, Drury, De Bresser and Pennock), pp. 1-27. The Geology Society, London, Special Publication. 200.

Durand, G., Persson, A., Samyn, D. \& Svensson, A. (2008) Relation between neighbouring grains in the upper part of the NorthGRIP ice core - Implications for rotation recrystallization. Earth Planet. Sci. Lett. 265, 666-671.

Duval, P., Ashby, M.F. \& Anderman, I. (1983) Rate-contolling processes in the creep of polycrystalline ice. J. Phys. Chem. 87, 4066-4074.

Erbe, E.F., Rango, A., Foster, J., Josberger, E. G., Pooley, C. \& Wergin, W.P. (2003) Collecting, shipping, storing, and imaging snow crystals and ice grains with low-temperature scanning electron microscopy. Microsc. Res. Technol. 62, 19-32.

Habesch, S.M. (2000) Electron backscattered diffraction analyses combined with environmental scanning electron microscopy: potential 
applications for non-conducting, uncoated mineralogical samples. Mater. Sci. Technol. 16(11-12), 1393-1398.

Hamann, I., Weikusat, C., Azuma, N. \& Kipfstuhl, S. (2007) Evolution of ice crystal microstructures during creep experiments. J. Glaciol. 53(182), $479-489$.

Humphreys, F.J. \& Hatherly, M. (2004) Recrystallization and Related Annealing Phenomena, 2nd edn., Elsevier, pp. 121-167.

Humphreys, F.J., Huang, Y., Brough, I. \& Harris, C. (1999) Electron backscatter diffraction of grain and subgrain structures - resolution considerations. J. Microsc. 195(3), 212-216.

Humphreys, F.J., Bate P.S. \& Hurley, P.J. (2001) Orientation averaging of electron backscattered diffraction data. J. Microsc. 201(1), 50-58.

Humphreys, F.J. (2001) Review - Grain and subgrain characterization by electron backscatter diffraction. J. Mater. Sci. 36(16), 3833-3854.

Humphreys, F.J. (2004) Characterization of fine-scale microstructures by electron backscatter diffraction (EBSD). Scr. Mater. 51, 771-776.

Hurley, P.J. \& Humphreys, F.J. (2002) Characterizing the deformed state in $\mathrm{Al}-0.1 \mathrm{Mg}$ alloy using high resolution electron backscattered diffraction. J. Microsc. 205, 218-225.

Huybrechts, P. (2007) Ice Sheet Modeling. Encyclopedia of the Antarctic (ed. by Riffenburgh, B.), pp. 514-517. Routledge, New York and London.

Iliescu, D., Baker, I. \& Chang, H. (2004) Determining the orientations of ice crystals using electron backscatter patterns. Microsc. Res. Technol. 63, 183-187.

IPCC (2007) Summary for Policymakers. Climate Change (2007): The Physical Science Basis. Contribution of Working Group I to the Fourth Assessment Report of the Intergovernmental Panel on Climate Change (ed. by Solomon, S., Qin, D., Manning, M., Chen, Z., Marquis, M., Averyt, K., M. Tignor \& Miller, H.), Cambridge University Press, Cambridge, United Kingdom and New York, NY, USA.

Kipfstuhl, S., Hamann, I., Lambrecht, A., Freitag, J., Faria, S.H., Grigoriev, D. \& Azuma, N. (2006) Microstructure mapping: a new method for imaging deformation induced microstructural features of ice on the grain scale. J. Glaciol. 52(178), 398-406.

Kipfstuhl, S., Faria, S.H., Azuma, N., et al. (2009) Evidence of dynamic recrystallization in polar firn. J. Geophys. Res. 114, B05204-1-10.

Lemke, P., Ren, J., Alley, R., et al. (2007) Observations: Changes in snow, ice and frozen ground. Climate Change (2007): The Physical Science Basis. Contribution of Working Group I to the Fourth Assessment Report of the Intergovernmental Panel on Climate Change (ed. by Solomon, S., Qin, D., Manning, M., Chen, Z., Marquis, M., Averyt, K., Tignor, M. \& Miller, H.), pp. 337-383. Cambridge University Press, Cambridge, United Kingdom and New York, NY, USA.

Miyamoto, A., Shoji, H., Hori, A., Hondoh, T., Clausen, H. \& Watanabe, O. (2005) Ice fabric evolution process understood from anisotropic distribution of a-axis orientation on the GRIP (Greenland) ice core. Ann. Glaciol. 42, 47-52.

Montagnat, M., Duval, P., Bastie, P., Hamelin, B. \& Lipenkov, V.Y. (2003) Lattice distortion in ice crystals from the Vostok core (Antarctica) revealed by hard X-ray diffraction; implication in the deformation of ice at low stresses. EPSL 214, 369-378.

Obbard, R., Baker, I. \& Sieg, K. (2006) Using electron backscatter diffraction patterns to examine recrystallization in polar ice sheets. $J$. Glaciol. 52(179), 546-557.

Obbard, R. \& Baker, I. (2007) The microstructure of meteoric ice from Vostok, Antarctica. J. Glaciol. 53(180), 41-62.

Oerter, H., Drücker, C., Kipfstuhl, S. \& Wilhelms, F. (2009) Kohnen station - the drilling camp for the EPICA deep ice core in Dronning Maud Land. Polarforschung 78, 1-23.

Piazolo, S., Montagnat, M. \& Blackford, J.R. (2008) Sub-structure characterization of experimentally and naturally deformed ice using cryo-EBSD. J. Microsc. 230, 509-519.

Randle, V. \& Engler, O. (2000) Introduction to Texture Analysis: Macrotexture, Microtexture and Orientation Mapping, Taylor \& Francis, London, p. 388.

Rango, A., Wergin, W.P., Erbe, E.F. \& Josberger, E.G. (2000) Snow crystal imaging using scanning electron microscopy: III. Glacier ice, snow and biota. Hydrol. Sci. J. 45(3), 357-375.

Suzuki, S. (1970) Grain coarsening of microcrystals of ice. (III). Low Temp. Sci. Ser. A, 28, 47-61.

Vaughan, D. \& Arthern, R. (2007) Why is it hard to predict the future of ice sheets? Science 315, 1503-1504.

Wang, Y. \& Azuma, N. (1999) A new automatic ice-fabric analyzer which uses image-analysis techniques. Ann. Glaciol. 29, 155-162.

Wang, Y., Kipfstuhl, S., Azuma, N., Thorsteinsson, T. \& Miller, H. (2003) Ice-fabrics study in the upper $1500 \mathrm{~m}$ of Dome C (East Antarctica) deep ice core. Ann. Glaciol. 37, 97-104.

Waller, D., Stokes, D.J. \& Donald, A. (2005) Development of low temperature ESEM: exploring sublimation. Microsc. Microanal. 11(Suppl 2), 414-415.

Waller, D. Stokes, D.J. \& Donald, A.M. (2008) Improvements to a cryosystem to observe ice nucleating in a variable pressure scanning electron microscope. Rev. Sci. Intrum., 79, 10379-1 to 7.

Weikusat, I., Kipfstuhl, S., Faria, S.H., Azuma, N. \& Miyamoto, A. (2009a) Subgrain boundaries and related microstructural features in EPICADronning Maud Land (EDML) deep ice core. J. Glaciol. 55(191), 461472 .

Weikusat, I., Kipfstuhl, S., Azuma, N., Faria, S.H. \& Miyamoto, A. (2009b) Deformation Microstructures in an Antarctic Ice Core (EDML) and in Experimentally Deformed Artificial Ice. Physics of Ice Core Records II (ed. by T. Hondoh), pp. 115-123. Supplement Issue of Low Temperature Science 68, Sapporo.

Weikusat, I., Miyamoto, A., Faria, S.H., Kipfstuhl, S., Azuma, N. \&Hondoh, T. (2010) Subgrain boundaries in Antarctic ice quantified by X-ray Laue diffraction. J. Glaciol., in press.

Wesche, C., Eisen, O., Oerter, H., Schulte, D. \& Steinhage, D. (2007) Surface topography and ice flow in the vicinity of the EDML deep-drilling site, Antarctica. J. Glaciol. 53(182), 442-448. 